\section{A 80-year-old woman with B-cell prolymphocytic leukemia}

\author{
Alparslan Merdin, ${ }^{1}$ Jale Yıldız, ${ }^{1}$ \\ Mehmet Sinan Dal, ${ }^{1}$ \\ Merih Kızıl Çakar, ${ }^{1}$ Hikmetullah Batgi, ${ }^{1}$ \\ Emre Tekgündüz, ${ }^{1}$ Aykut Onursever, ${ }^{2}$ \\ Fevzi Altuntaş ${ }^{1}$ \\ ${ }^{1}$ Hematology Clinic and Bone Marrow \\ Transplantation Unit, and ${ }^{2}$ Pathology \\ Clinic, Dr. Abdurrahman Yurtaslan \\ Oncology Training and Research \\ Hospital, Ankara, Turkey
}

\begin{abstract}
Prolymhocytic leukemia (PLL) is a rare subtype of lymphocytic leukemias and its cells are immature lymphocytes. It is divided into 2 subgroups: T-PLL and B-PLL according to the lymphocytic origin of the cells. Discriminating B-PLL from other diseases with clinically-similar features is important because of the different treatment approaches and follow-up programs. Hereby, we report a 80-year-old woman presenting with fatigue, leucocytosis and mild anemia. Her peripheral blood smear evaluation revealed $85 \%$ prolymphocytes with moderately condensed nuclear chromatin, prominent nucleoli, and a faintly basophilic cytoplasm. Positron emission tomography-computed tomography showed mediastinal lymph nodes with cervical lymph nodes. There was no pathological FDG involvement in the spleen. Bone marrow aspiration smear exhibit atypical wide lymphocytes with prominent nucleoli and abundant agranular cytoplasm. Flow cytometry analysis revealed positive $\mathrm{CD}^{+}$, $\mathrm{CD} 19^{+}, \mathrm{CD} 20^{+}, \mathrm{CD} 22^{+}, \mathrm{CD} 11 \mathrm{c}^{+}, \mathrm{CD} 25^{+}$, $\mathrm{CD}_{79} \mathrm{a}^{+}$and $\mathrm{CD}_{79 \mathrm{~b}^{+}}$. Fluorescence in situ hybridization technique analysis reveals no $\mathrm{t}(11 ; 14)$. Bone marrow biopsy revealed interstitially distributed atypical cells with wide nucleus and prominent nucleolus.
\end{abstract}

\section{Introduction}

Prolymhocytic leukemia (PLL) cells are immature lymphocytes. And PLL is a rare subtype of lymphocytic leukemias. PLL is divided into two subgroups. The first is TPLL and the second is B-PLL according to the lymphocytic origin of the PLL cells. TPLL cells have $\mathrm{CD}^{+}, \mathrm{CD}^{+}, \mathrm{CD}^{+}, \mathrm{CD}^{+}$ cell surface markers. On the other side, $\mathrm{B}-$ PLL cells have $\mathrm{CD} 19^{+}$and $\mathrm{CD} 20^{+}$on the cells. $55 \%$ or more prolymphocytes circula- ting indicates prolymphocytic leukemia. This ratio is used in differentiating B-PLL from chronic lymphocytic leukemia(CLL). B-PLL is an extremely rare disease. Less than 1 percent of the $B$ cell leukemias has been found to be B- PLL. ${ }^{1}$

B-PLL might have similar clinical findings with some other leukemia forms. TPLL, CLL, hairy-cell leukemia variant (HCL-V), splenic marginal zone lymphoma (SMZL) and mantle cell lymphoma (MCL) are the most possible differential diagnostic diseases of B-PLL. Clinical discrimination of each disease is important due to the differences in treatment approaches and overall survival. Peripheral blood (PB) smear,flow cytometry, bone marrow (BM) biopsy, and imaging help to put the right diagnosis. ${ }^{2}$ Hereby, we report a 80 year old woman presenting with fatigue, leucocytosis and mild anemia.

\section{Case Report}

A 80-year-old woman presented to the emergency service with fatigue. She did not have any other known chronic diseases. Physical presentation revealed $2 \mathrm{~cm}$ palpable enlarged spleen below the costal margin, bilateral small cervical lymph nodes and no hepatomegaly. Her hemoglobin level was $11.2(12-18) \mathrm{g} / \mathrm{dL}$, platelet count was $260.000(130000-400.000) / \mu \mathrm{L}$, white blood cell count was $115.000 / \mu \mathrm{L}(4.200-11.000)$, neutrophil count was $7780(1900-8000) / \mu \mathrm{L}$, lymphocyte count was 25.440 (0.9$5.200) / \mu \mathrm{L}$ and LUC (large unstained cells) count was $81.200(0-0.5) / \mu \mathrm{L}$. Her blood chemistry was unremarkable, except for a lactate dehydrogenase level of 243 (125220) U/L, and beta- 2 microglobulin level of $5.3 \mathrm{mg} / \mathrm{L}$ (0.7-1.8). Peripheral blood smear evaluation showed $85 \%$ prolymphocytes with moderately condensed nuclear chromatin, prominent nucleoli, and a faintly basophilic cytoplasm (Figure 1). She had no monoclonal gammopathy in the serum and urine immunoelectrophoresis. PET-CT showed mediastinal lymph nodes with cervical lymph nodes. And the greatest size of mediastinal lymph nodes was $20 \times 12 \mathrm{~mm}$ and cervical lymph nodes was $8 \times 13 \mathrm{~mm}$. There was no pathological FDG involvement in the spleen. BM aspiration smear exhibit atypical wide lymphocytes with prominent nucleoli and abundant agranular cytoplasm (Figure 2). There were no cytoplasmic projections such as hairy projections or blebbings on the cell surface of the atypical lymhocytes (Figures 1 and 2).

Flow cytometry analysis revealed CD34 negative lymphocytes. Lymphocytes
Correspondence: Alparslan Merdin, Ankara Oncology Education and Research Hospital, Mehmet Akif Ersoy Mh., 13. Cadde No: 56, Mehmet Akif Ersoy, 06200 Ankara, Turkey. Tel.: +90.312.336.0909.

E-mail: alparslanmerdin@yahoo.com

Key words: B cell prolymphocytic leukemia; chronic lymphocytic leukemia.

Contributions: the authors contributed equally.

Conflict of interest: the authors declare no potential conflict of interest.

Poster presentation: the abstract was presented as a poster in the $11^{\text {th }}$ National Apheresis Congress, 2016, Turkey. Abstract No: O2

Received for publication: 2 December 2016. Revision received: 3 February 2017.

Accepted for publication: 5 February 2017.

This work is licensed under a Creative Commons Attribution-NonCommercial 4.0 International License (CC BY-NC 4.0).

CCopyright A. Merdin et al., 2017

Licensee PAGEPress, Italy

Hematology Reports 2017; 9:6995

doi:10.4081/hr.2017.6995

had negative $\mathrm{CD}^{-} 3^{-}, \mathrm{CD}^{-} 3^{-}, \mathrm{CD}^{-1} 7^{-}$, CD23-, FMC7-, MPO-, CD15-, CD14-, CD64-. And lymphocytes had positive $\mathrm{CD}^{+}, \mathrm{CD} 19^{+}, \mathrm{CD} 20^{+}, \mathrm{CD} 22^{+}, \mathrm{CD} 11 \mathrm{c}^{+}$, $\mathrm{CD} 25^{+}, \mathrm{CD} 79 \mathrm{a}^{+}$and CD79b $\mathrm{b}^{+}$. Fluorescence in situ hybridization (FISH) technique analysis reveals no translocation between the 11th and 14th chromosome. BM biopsy revealed interstitially distributed atypical cells with wide nucleus and prominent nucleolus (Figure 3). Immunohistochemical staining of the atypical cells showed diffuse CD20, PAX5, CD5, BCL2 positivity and partial CD23 strong positivity (Figure 4). TDT, CD10, CD34, CD117, BCL1, BCL6, SOX11 and Annexin were not detected on the atypical cells. Besides, CD25 was weakly and non-specifically detected by staining. Lower rate of lymphocytes with small size were detected to have CD3 by staining. Lastly, reticulin fiber was not increased (grade 0/3). BM biopsy was reported as primarily compatible with prolymphocytic leukemia for the diagnosis.

\section{Discussion}

B-PLL is a very rare disease. And it might not be kept in mind especially in the patients with the presentation of clinically similar features sharing diseases. Discrimination of B-PLL from the other cli- 
nically similar features sharing diseases are important because of the different treatment approaches and different follow-up programs. The best first line treatment for T-PLL is alemtuzumab. ${ }^{2}$ Alemtuzumab could also be used in B-PLL. ${ }^{2-4}$ Fludarabine, cyclophosphamide and rituximab could also be used as part of other effective chemotherapy regimens for the treatment of B-PLL. ${ }^{2,5-7}$ Morphology, flow cytometric analysis and pathology help to put the accurate diagnosis. Unlike B-PLL, T-PLL cells have T cell markes detected by flow cytometry.

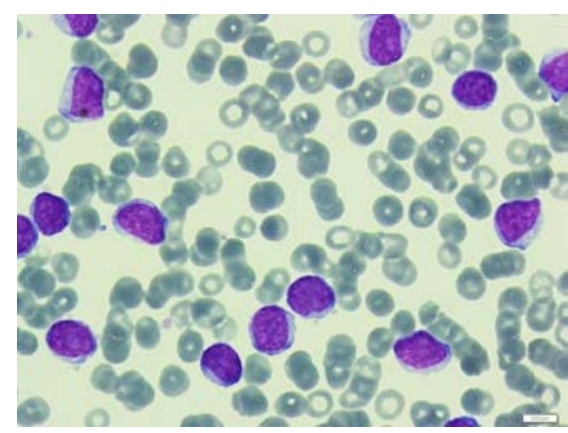

Figure 1. Peripheral smear: atypical wide lymphocytes with prominent single nucleoli and abundant agranular cytoplasm

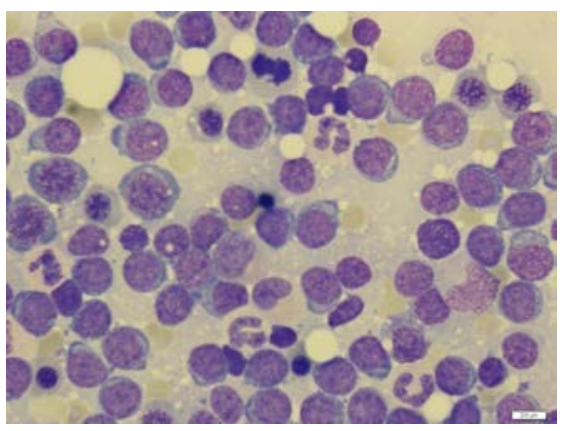

Figure 2. Bone marrow aspiration: atypical wide lymphocytes with prominent nucleoli and abundant agranular cytoplasm.

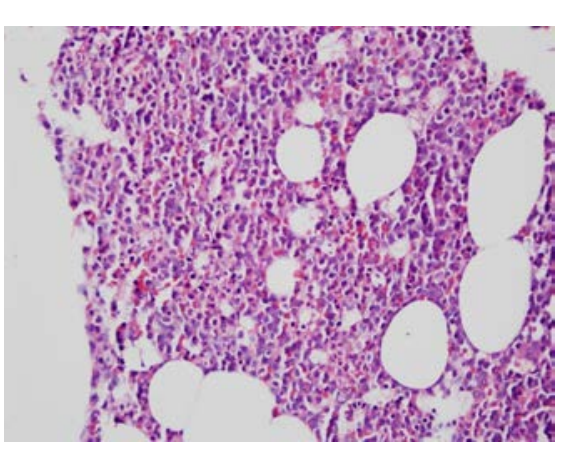

Figure 3. Huge atypical cells between normal hematopoietic cells in the bone marrow biopsy sample.
Lymphocytes of our patient had $\mathrm{CD} 19^{+}$and $\mathrm{CD} 20^{+}$on flow cytometric analysis. And this feature of flow cytometric analysis made us far from the diagnosis of T-PLL. HCL- $\mathrm{V}$ is also a rare entity which has intermediate properties between hairy cell leukemia and B-PLL. ${ }^{8}$ HCL-V cells usully lack CD25- on the cell. ${ }^{9,10}$ But flow cytometric analysis of our patient showed strong positivity for $\mathrm{CD} 25^{+}$. And immunohistochemical staining of the atypical cells of our patient also showed weakly and non-specifically staining for CD25. Besides, atypical cells of our patient did not have cytoplasmic projections. So that, our patiets clinical findings are not suitable for the diagnosis of HCL-V.

SMZL is a rare indolent B-cell lymphoma involving spleen, BM, and frequently the blood. ${ }^{11}$ Peripheral blood atypical lymphocyte morphology consists of villous lymphocytes with basophilic cytoplasm. ${ }^{11,12}$ Franco et al. reported that bone marrow (BM) infiltration of the SMZL was mostly of the intrasinusoidal type and BM infiltration tended to become frankly nodular after splenoctomy. ${ }^{13}$ On the other side, atypical neoplastic lymphocytes of our patient did not have villous projections. And our patient did not have massive splenomegaly and pathological splenic FDG involvement. The pathological infiltration of the $\mathrm{BM}$ in our patient was interstitial unlike the
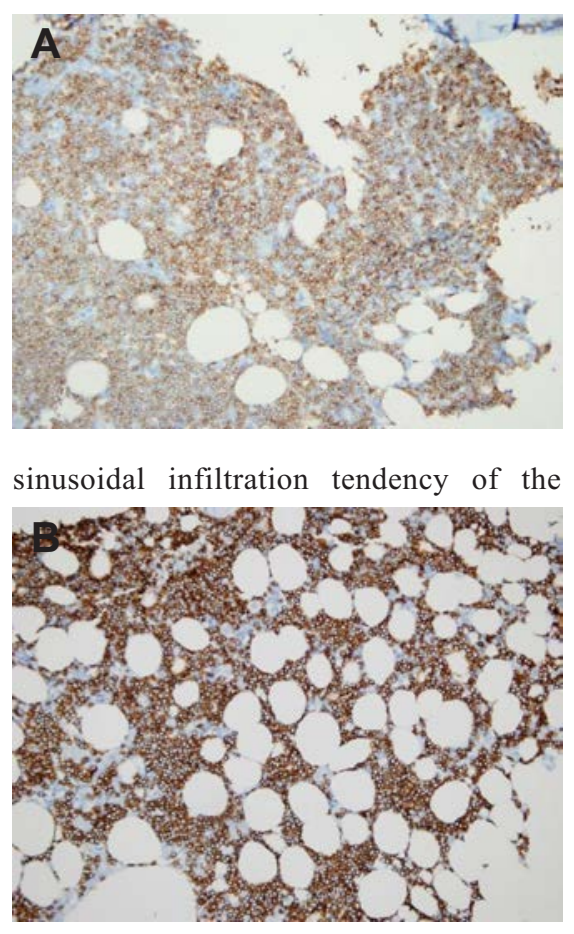

Figure 4. Diffuse CD5 (A) and CD20 (B) positivity in the bone marrow biopsy sample.
SMZL.Besides, FISH technique analysis of our patient was negative for $\mathrm{t}(11 ; 14)$. BCL1 was not detected on the atypical cells taken by the biopsy. These findings also exclude the diagnosis of MCL.

\section{Conclusions}

In conclusion, we should think of BPLL in case of high circulating prolymphocyte counts with prominent nucleoli and without villous projections in the peripheral smear. And we should also keep in mind some other clinically similar features sharing disorders such as SMZL, HCL-Variant T-PLL in the differential diagnosis. Lastly, morphology and flow cytometry analysis will help to make the accurate diagnosis.

\section{References}

1. Yamamoto JF, Goodman MT. Patterns of leukemia incidence in the United States by subtype and demographic characteristics, 1997-2002. Cancer Causes Control 2008;19:379.

2. Dearden C. How I treat prolymphocytic leukemia. Blood 2012;120:538-51.

3. Chaar BT, Petruska PJ. Complete response to alemtuzumab in a patient with B prolymphocytic leukaemia. Am J Hematol 2007;82:417.

4. Bowen AL, Zomas A, Emmett E, et al. Subcutaneous CAMPATH-1H in fludarabine-resistant/relapsed chronic lymphocytic and B-prolymphocytic leukaemia Br J Haematol 1997;96:6179.

5. Sibbald R, Catovsky D. Complete remission in prolymphocytic leukaemia with the combination chemotherapy CHOP. Br J Haematol 1979;42:488-90.

6. Herold M, Spohn C, Schlag R, et al. Fludarabine/cyclophosphamide chemotherapy for B-prolymphocytic leukaemia [abstract]. Blood (ASH Annual Meeting Abstracts) 2003;102. Abstract 2499.

7. Chow KU, Kim SZ, von Neuhoff N, et al. Clinical efficacy of immunochemotherapy with fludarabine, epirubicin and rituximab in the treatment for chronic lymphocytic leukaemia and prolymphocytic leukaemia. Eur J Haematol 2011;87:426-33.

8. Robak T. Hairy-cell leukemia variant: recent view on diagnosis, biology and treatment. Cancer Treat Rev 2011;37:310.

9. Matutes E, Wotherspoon A, Catovsky D. The variant form of hairy-cell leuke- 
mia. Best Pract Res Clin Haematol 2003;16:41-56.

10. Cessna MH, Hartung L, Tripp S, et al. Hairy cell leukemia variant: fact or fiction. Am J Clin Pathol 2005;123:132-8.

11. Arcaini L, Rossi D, Paulli M. Splenic marginal zone lymphoma: from gene- tics to management. Blood 2016;127:2072-81.

12. Traverse-Glehen A, Baseggio L, Bauchu EC, et al. Splenic red pulp lymphoma with numerous basophilic villous lymphocytes: a distinct clinicopathologic and molecular entity? Blood
2008; 111:2253-60.

13. Franco V, Florena AM, Stella M, et al. Splenectomy influences bone marrow infiltration in patients with splenic marginal zone cell lymphoma with or without villous lymphocytes. Cancer 2001;91:294-301. 